The Federal Reserve BanK of KANSAS City Research Working Papers

\title{
Uncertainty and Fiscal Cliffs
}

Troy Davig and Andrew Foerster

April 2014

RWP 14-04 


\title{
Uncertainty and Fiscal Cliffs*
}

\author{
Troy Davig ${ }^{\dagger} \quad$ Andrew Foerster ${ }^{\ddagger}$
}

April 4, 2014

\begin{abstract}
Motivated by the US Fiscal Cliff in 2012, this paper considers the short- and longerterm impact of uncertainty generated by fiscal policy. Empirical evidence shows increases in economic policy uncertainty lower investment and employment. Investment that is longer-lived and subject to a longer planning horizon responds to policy uncertainty with a lag, while capital that depreciates more quickly and can be installed with few costs falls immediately. A DSGE model incorporating uncertainty over future tax regimes produces responses to fiscal uncertainty that match key features of the data. The model features uncertainty over the average tax rate and rational expectations about the resolution of uncertainty with specific outcomes and timing. Uncertainty injects noise into the economy and lowers the level of economic activity.
\end{abstract}

JEL Classification: E20, E60, E62

Keywords: Fiscal Policy, Uncertainty, Distorting taxation

*The views expressed herein are solely those of the authors and do not necessarily reflect the views of the Federal Reserve Bank of Kansas City or the Federal Reserve System. We thank Alejandro Justiniano, Ben Johannsen, Mike Dotsey, and seminar participants at the Missouri Economics Conference, Florida State, the North American Summer Meetings of the Econometric Society, Korea Development Institute, the Computing in Economics and Finance Conference, Kansas, the NBER Workshop on DSGE Models, and the Midwest Macroeconomics Conference for helpful comments.

${ }^{\dagger}$ Research Department, Federal Reserve Bank of Kansas City, 1 Memorial Drive, Kansas City, MO 64198, troy.davig@kc.frb.org.

${ }^{\ddagger}$ Research Department, Federal Reserve Bank of Kansas City, 1 Memorial Drive, Kansas City, MO 64198, andrew.foerster@kc.frb.org. 


\section{Introduction}

Fiscal uncertainty arises in many forms. Expiring temporary stimulus measures, projections of rapid debt growth, and oscillating political concerns over general levels of taxation all contribute to fiscal uncertainty. In the US, a particularly stark example occurred in the summer of 2011 as the US federal government approached its statutory borrowing limit. A default on US debt was avoided, but only due to a temporary compromise to impose fiscal restraint in the future. The restraint, however, was set to take effect at the same time that a package of earlier tax cuts were set to expire. The confluence of the various policies all were set to take effect starting in 2013, resulting in the so-called "Fiscal Cliff" that was a common topic among policymakers and the public throughout much of 2012. Looking ahead in the US, longer-term projections of rapid debt growth also raise questions about future fiscal policy.

Although aspects of fiscal uncertainty vary in particular details, such uncertainty has a two unique features. First, fiscal uncertainty often revolves around the potential for a specific set of changes to the average tax rate or level of government spending. Rather than a mean-preserving spread over a continuum of possible changes, episodes such as the Fiscal Cliff generally involve two possible outcomes: the passing of legislation to avoid the Cliff and thereby maintain the current structure of fiscal policy, or hit the Cliff and adjust towards the well-defined alternative. The discrete nature of possible policy changes are often not mean preserving, which eliminates many outcomes that could occur if changes in policy were instead viewed as a mean-preserving over a continuum of outcomes.

A second particular aspect of fiscal uncertainty is that fiscal reforms often have specific dates in the future that serve as decision points. In the recent US Fiscal Cliff episode, the end of 2012 served as the critical date when Congress would either pass legislation preserving the structure of fiscal policy, or a wide range of previous laws would expire leading to a major fiscal policy shift. In the lead-up to the decision date, a high degree of uncertainty about future policy prevails, but uncertainty is forced to be resolved at the decision point. 
This paper studies the effects of uncertainty generated by expiring taxes, such as that associated with the Fiscal Cliff in the US. It empirically documents that uncertainty about economic policy causes declines in employment and investment, although the exact nature of the investment decline varies by the type of capital. The paper then presents a model that captures the two important features of fiscal uncertainty: a set of possible future tax regimes and a specific future resolution date. The model generates responses to uncertainty that match key features of the data, such as a slow-down in employment and investment leading up to the decision point, as well as dynamics after uncertainty is resolved. Finally, the framework gives agents in the economy rational expectations over how the uncertainty may be resolved, so the paper studies how different expectation structures affect outcomes.

A large number of papers study the economic effects of uncertainty about the future. Bloom (2009) shows that after an increase in uncertainty, firms pause in their hiring and investing, with an overshooting response in the future. Basu and Bundick (2012), Bloom et al. (2012), and Leduc and Liu (2012) argue that uncertainty shocks are important drivers of fluctuations, Christiano et al. (2014) show how uncertainty can interact with financial frictions, and Fernández-Villaverde et al. (2011) show that higher volatility has large impacts in emerging economies.

Fiscal uncertainty represents a specific source of uncertainty included in general uncertainty about economic policy. Baker et al. (2013) develop an economic policy uncertainty index and show that increases in policy uncertainty lower investment and employment. Figure 1 shows the Fiscal Cliff period-shown by the dotted line-generated one of the highest readings for the policy uncertainty index, exceeded only by the combination of the debt ceiling dispute and the Euro debt crisis. This paper adds to the literature on the effects of uncertainty by empirically documenting that increases in policy uncertainty generate different responses in investment according to the type of capital.

Rather than a consideration of general policy uncertainty, which includes uncertainty about inflation and spending, this paper focuses on uncertainty generated by expiring tax 
Figure 1: Expiring Tax Provision Index (Baker, et al. (2013))

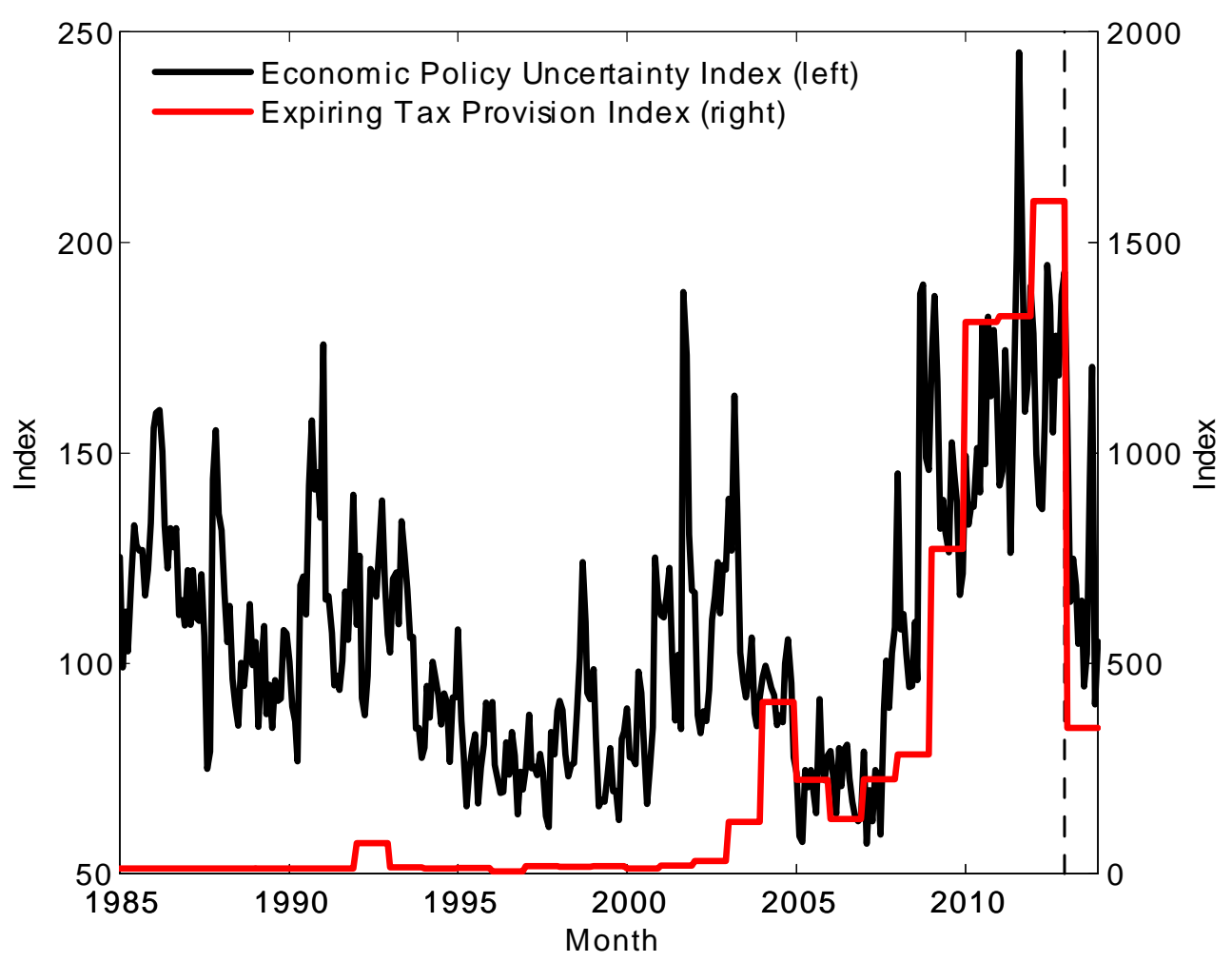

provisions-a large component of the Fiscal Cliff. The economic policy uncertainty index includes a measure of expiring tax provisions, which Figure 1 shows increased substantially in recent years. The increased use of expiring tax provisions starting in 2000 suggests that episodes similar to that studied in this paper may be increasingly important in the future. In addition, the results in this paper imply the use of automatic sunset provisions, which have legislation expire after a certain number of years in an attempt to prevent outdated laws from persisting, may have the unintended consequence of adding uncertainty.

Expiring provisions have two possible outcomes-either Congress extends the provisions or lets them expire-and a specific future date as a decision point-the end of the year. As a result, defining uncertainty as a mean-preserving spread in tax processes that dissipates over time may not capture some first-order implications of uncertainty generated by episodes similar to the Fiscal Cliff. For example, Fernández-Villaverde et al. (2012) estimate sto- 
chastic volatility processes for taxes and spending and show that inserting this process into a New Keynesian model produces adverse effects on economic activity. These stochastic volatility processes, however, imply symmetric distributions for the realizations of future shocks-implying that taxes and spending may increase or decrease-while this paper assumes that the tax policy may stay the same or it may adjust to a specific alternative. In addition, uncertainty never gets resolved under stochastic volatility. Instead, the processes governing fiscal policy gradually return to their normal volatility, whereas the model in this paper considers uncertainty that has a resolution date.

The model in this paper assumes rational expectations, which implies that household and firms understand current fiscal policy as well as possible changes in the future. In this setting, an uncertainty shock implies the arrival of new information that policy may change in the future. Other papers, such as Davig (2004), Hollmayr and Matthes (2013) or Richter and Throckmorton (2013), assume agents in the economy learn about the fiscal policy rule in place, and uncertainty increases the volatility in the economy. In this setup, the economy doesn't face an uncertainty shock, but simply has changes in policies that agents must learn.

A fiscal uncertainty shock associated with a future resolution date resembles a news shock. Rather than a perfectly known change, as in Jaimovich and Rebelo (2009), or a noisy signal, as in Schmitt-Grohé and Uribe (2012) and Born et al. (2013), a fiscal uncertainty shock can be interpreted as information about a change in the policy rule in the future that may or may not be realized.

Finally, a large body of research studies the fact that uncertainty over discrete changes in future fiscal policy affect the economy in the short term. For example, Chung et al. (2007), Davig and Leeper (2011), Bianchi (2012), and Bianchi and Melosi (2013) all note that the potential for switches in the fiscal policy rule matter for how the economy responds to shocks. However, these papers do not have a well-defined concept of an uncertainty shock, which this paper introduces to this literature.

The paper proceeds as follows. Section 2 presents empirical evidence on the effects of 
policy uncertainty. Based upon this evidence, Section 3 discusses a model that captures the main features of the Fiscal Cliff. Using this model, Section 4 shows the impact of fiscal uncertainty. Section 5 highlights how expectations interact with uncertainty, and Section 6 concludes.

\section{Empirical Evidence}

Before turning to the theoretical model, this section considers the effects of economic policy uncertainty on activity. To accomplish this goal, consider a vector-autoregression (VAR) model using the economic policy uncertainty (EPU) index in Baker et al. (2013). The effects of uncertainty in this framework are captured by how investment and employment respond to an identified shock to the EPU index. The benchmark VAR contains the EPU index, private employment from the Current Establishment Survey, and real investment in structures and equipment from the National Income and Product Accounts. The EPU index is in levels, while the investment and employment are in quarter-over-quarter, annualized percentage changes. The VAR has four lags. The sample is at a quarterly frequency and runs from 1986 Q1 to 2013 Q3.

The structural shocks are identified using a Cholesky decomposition with the EPU index ordered first. The ordering implies that the EPU index does not respond contemporaneously to macroeconomic developments, but that investment and employment growth can change on impact to an EPU shock. Figure 2 shows the impulse responses to an identified two standard deviation shock to the EPU index. In response to the shock, both investment and employment growth decline over several quarters. Private-nonresidential investment growth falls by about 2 percentage points at an annualized rate for 5 quarters. Private employment growth declines as well, falling by over 0.5 percentage points at the trough.

The immediate decline in investment growth shown in Figure 2 masks some of the effects of an EPU shock. For example, certain types of investment may respond quickly to 
Figure 2: Impact of a Shock to the Economic Policy Uncertainty Index
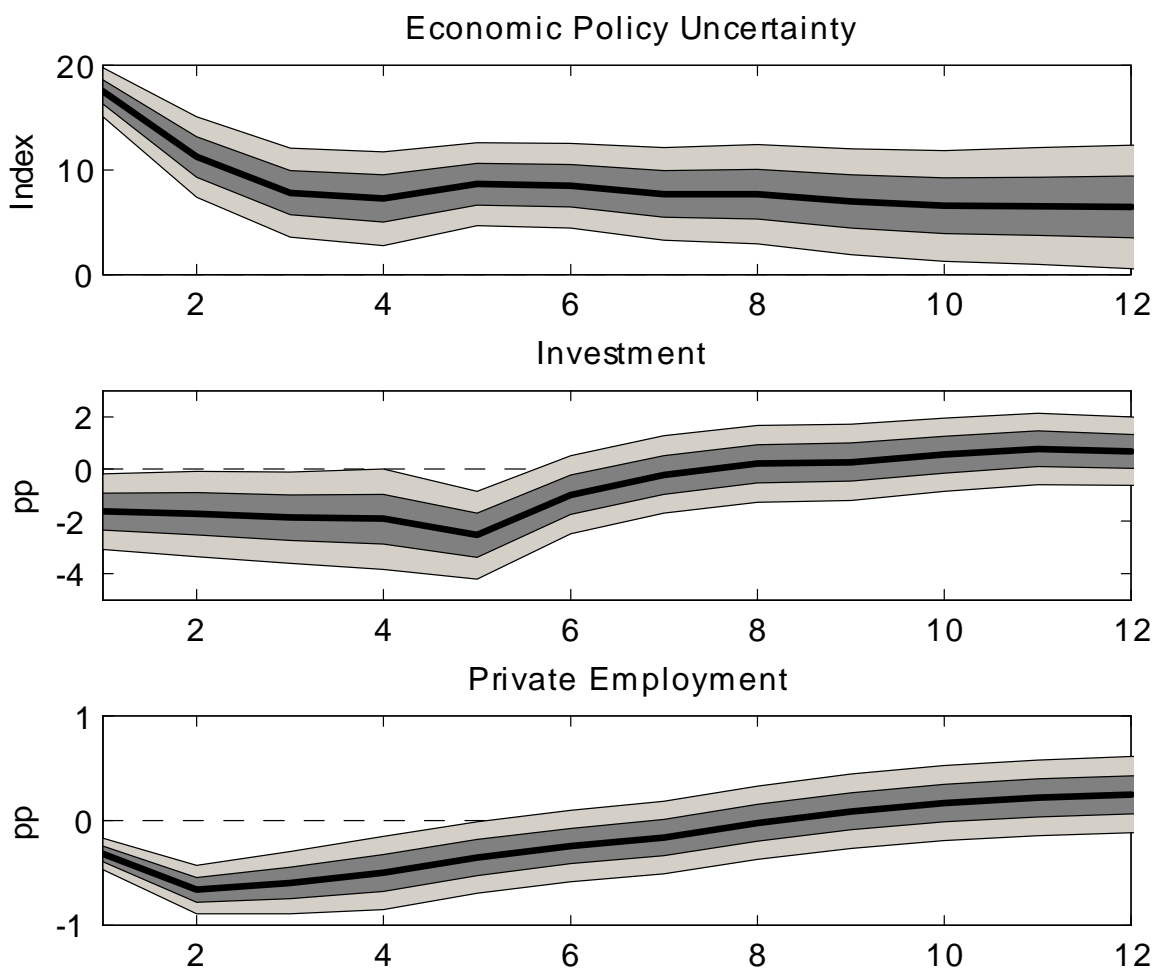

policy uncertainty while others may respond more slowly. Now consider an additional VAR separating investment into two components: structures and equipment. Investment in structures typically requires a lengthy implementation process, after which it depreciates relatively slowly. On the other hand, equipment can be purchased and installed relatively quickly, and faces more rapid depreciation. Longer implementation time may cause slower responses to new information, since large investment projects already put in motion may be difficult to reverse. Similarly, lower depreciation rates may allow a greater degree of postponing investment, since the existing capital stock can be used for longer. Both of these factors imply equipment investment may respond more quickly to uncertainty shocks than structures investment.

Figure 3 depicts the impulse responses to an identified two standard deviation shock to the EPU index in the VAR with investment split into the different components. As antici- 
Figure 3: Impact of a Shock to the Economic Policy Uncertainty Index, Two Capital Types
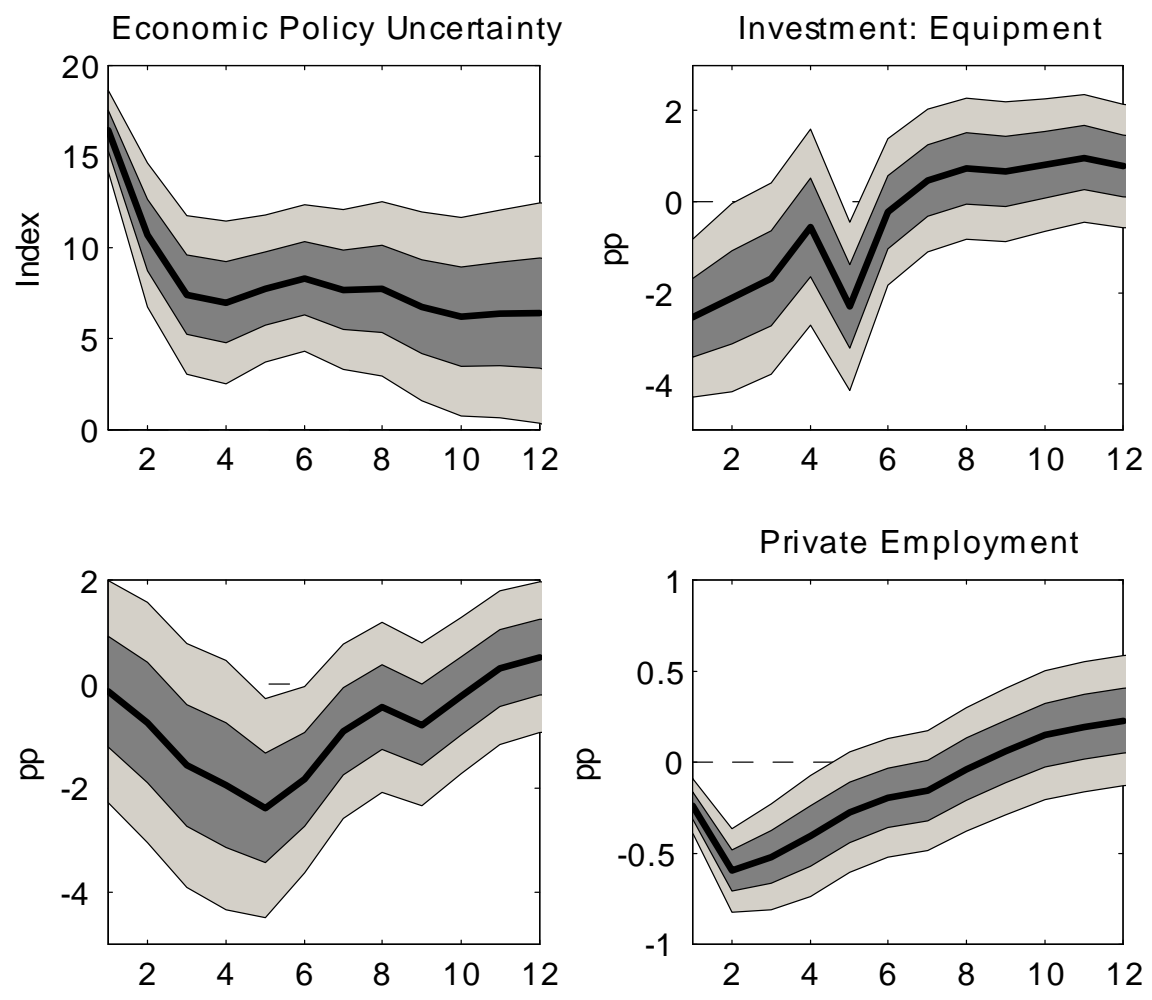

pated, the two types of investment show markedly different responses. Annualized growth in equipment investment declines immediately on impact by 2.5 percentage points, but the decline only lasts two quarters. By comparison, the response of investment in structures shows a slower moving decline. On impact, structures investment growth does not respond, but then falls about 2.5 percentage points after 5 quarters.

The results demonstrate that employment and investment both decline in response to an increase in economic policy uncertainty, as measured by the EPU index. Importantly, investment in structures responds with a lag, suggesting that possible adjustment frictions and a lower depreciation rate lead firms to not reduce investment immediately after a shock. On the other hand, investment in new equipment shows an immediate decline, since it is not subject to the same adjustment frictions and tends to depreciate faster. The next section presents a model that captures these features of the data. 


\section{Model Overview}

This section describes the model, including the representative household, the representative firm, and fiscal policy, followed by a discussion of the evolution of uncertainty, how to quantify fiscal uncertainty, and the parameterization.

\subsection{Households}

The representative household has preferences over consumption $C_{t}$ and labor $L_{t}$ as in Jaimovich and Rebelo (2009), restricted to the case of King et al. (1988) preferences. That is, it maximizes

$$
\mathbb{E}_{0} \sum_{t=0}^{\infty} \beta^{t} \frac{\left(C_{t}\left(1-\psi L_{t}^{\theta}\right)\right)^{1-\gamma}-1}{1-\gamma}
$$

where $\beta \in(0,1)$ denotes the discount factor, $\gamma>0$ the coefficient of relative risk aversion, $\psi>0$ the disutility of labor, and $\theta>1$ controls the elasticity of labor supply.

Given evidence in Section 2 that the response of investment in equipment differs compared to structures following a policy uncertainty shock, the model has two capital types, denoted $K_{1, t}$ and $K_{2, t}$. Households choose consumption $C_{t}$, labor $L_{t}$, investment in the two capital types $I_{1, t}$ and $I_{2, t}$, and purchase bonds $B_{t}$ to maximize (1) subject to the budget constraint

$$
C_{t}+I_{1, t}+I_{2, t}+B_{t} \leq\left(1-\tau_{t}\right)\left(U_{1, t} K_{1, t-1}+U_{2, t} K_{2, t-1}+W_{t} L_{t}\right)+R_{t-1} B_{t-1}
$$

where $U_{1, t}$ and $U_{2, t}$ denote the real rental rate on the two capital types, $W_{t}$ denotes the real wage rate, $R_{t-1}$ the real return on bonds, and $\tau_{t}$ the time-varying distortionary tax rate on income.

Each type of capital is subject to its own accumulation equation, with distinct adjustment costs and depreciation rates. The first type of capital is subject to adjustment costs in the 
change in investment, so capital accumulation follows

$$
K_{1, t}=\left(1-\delta_{1}\right) K_{1, t-1}+I_{1, t}\left(1-\frac{\varphi}{2}\left(\frac{I_{1, t}}{I_{1, t-1}}-1\right)^{2}\right)
$$

where $\delta_{1}$ denotes the rate of depreciation and $\varphi$ the degree of adjustment costs. The second capital type has no adjustment cost and accumulates according to

$$
K_{2, t}=\left(1-\delta_{2}\right) K_{2, t-1}+I_{2, t},
$$

where $\delta_{2}$ denotes the depreciation rate. In this setup, capital type $K_{1, t}$ responds more sluggishly than $K_{2, t}$ to investment depending on the adjustment cost parameter $\varphi$. These processes interpret $K_{1, t}$ as structures and $K_{2, t}$ as equipment.

\section{$3.2 \quad$ Firms}

The perfectly competitive, representative firm produces output $Y_{t}$ using the Cobb-Douglas production technology

$$
Y_{t}=K_{1, t-1}^{\alpha_{1}} K_{2, t-1}^{\alpha_{2}} L_{t}^{1-\alpha_{1}-\alpha_{2}}
$$

where $\alpha_{1}$ and $\alpha_{2}$ denote the respective capital shares. The firm makes production decisions by solving a series of one-period problems, maximizing profits and taking the rental rates $U_{1, t}$ and $U_{2, t}$, and the wage rate $W_{t}$ as given. Assuming an interior solution, firms maximize profits by equating marginal products with factor prices.

\subsection{Fiscal Policy}

To focus analysis on the effects of changes in the tax rate, government spending is constant $G_{t}=\bar{G}=g Y_{s s}$ for all $t$, where $g$ denotes the fraction of steady state output $Y_{s s}$. Given this 
restriction, debt evolves according to

$$
B_{t}=R_{t-1} B_{t-1}+\bar{G}-\tau_{t} Y_{t}
$$

where the government must pay the real rate of return of $R_{t-1}$ on outstanding bonds. In equilibrium, the quantity of bonds willingly held be the representative agent, $B_{t}$, must equal the aggregate level of government debt.

All uncertainty is associated with the income tax rate, which follows the debt feedback rule

$$
\tau_{t}=\mu\left(S_{t}\right)+\lambda B_{t-1}+\varepsilon_{t},
$$

where the error $\varepsilon_{t}$ follows an auto-regressive process

$$
\varepsilon_{t}=\rho \varepsilon_{t-1}+\sigma u_{t}
$$

with $u_{t} \sim N(0,1)$ and $\mathbb{E}\left[u_{t} u_{s}\right]=0$ for $s \neq t$. Innovations in $u_{t}$ represent intra-regime shocks and changes in $S_{t}$ represent regime shifts. The intercept in (7) governs the regime-dependent average level of taxation and debt, and takes one of two values

$$
\mu\left(S_{t}\right) \in\left\{\mu_{0}, \mu_{1}\right\}
$$

The next subsection discusses how $\mu\left(S_{t}\right)$ evolves over time.

Given there is no long-run growth and the real interest rate is positive, the transversality condition holds if debt does not grow faster than the real interest rate. To satisfy this condition, parameters in the tax rule must generate sufficient tax revenue to stabilize the debt-to-output ratio in each regime. In linearized versions of this model, the condition requires $\lambda>1 / \beta$.

The debt feedback in the tax rule (7) generates an inverse relationship between the intercept term $\mu\left(S_{t}\right)$ and the level of taxes in the long run. In steady state, larger values of 
Figure 4: Fiscal Uncertainty

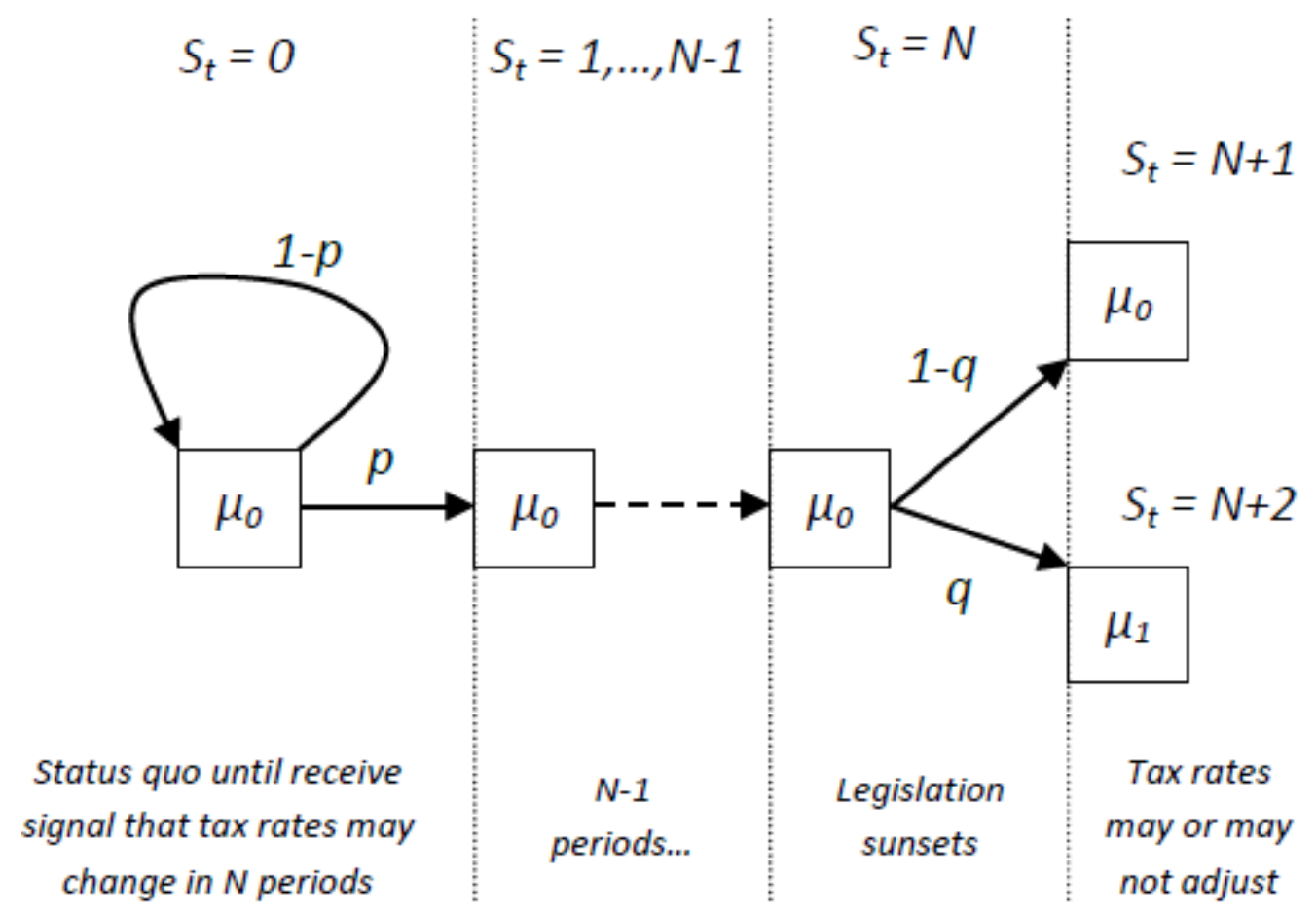

$\mu\left(S_{t}\right)$ are associated with lower debt levels, which produces lower income tax rates. Higher average tax rates can support higher interest costs, so a high average tax rate implies higher debt. When $\mu\left(S_{t}\right)$ changes from a low value to a higher one, tax rates can move temporarily higher as debt is paid down. Eventually, as debt declines, lower tax rates follow as the economy transitions to a state with less debt.

\subsection{Information Structure}

Figure 4 illustrates the flow of information and how uncertainty is resolved. In $S_{t}=0$, households place probability $p$ on receiving information in each period, which constitutes a fiscal uncertainty shock. This shock signals a new tax regime may be in place after $N$ periods. Absent a shock, households understand in this regime that a future adjustment in the tax rate is possible, but view the timing as uncertain. In addition, given a low probability of an uncertainty shock $p$, the $S_{t}=0$ regime reflects the status quo. 
With probability $p$ each period, the economy receives an uncertainty shock that moves it from $S_{t}=0$ to $S_{t}=1$. This regime change has the flavor of a news shock, as no fundamental policy parameters actually change. The shift, however, provides households with a clear calendar regarding the timing of a possible adjustment to tax rates. If a fiscal uncertainty shock is realized, households anticipate after $N$ periods the fiscal authority will keep the existing tax rate governed by $\mu_{0}$ with probability $1-q$, and adjust to $\mu_{1}$ with probability $q$.

Since households understand tax rates could change after the $N$ period horizon, they begin adjusting their behavior immediately in response to the fiscal uncertainty shock, which is upon the realization of $S_{t}=1$. In the baseline scenario $N=4$, so uncertainty about the future tax regime lasts for four quarters.

A Markov-switching framework captures the timing and resolution of uncertainty within this information structure. In total, there are $N+3$ regimes, where $S_{t} \in\{0,1, \ldots, N+2\}$ indicates the regime. For the case of $N=4$, the transition matrix is

$$
\Pi=\left[\begin{array}{ccccccc}
1-p & p & 0 & 0 & 0 & 0 & 0 \\
0 & 0 & 1 & 0 & 0 & 0 & 0 \\
0 & 0 & 0 & 1 & 0 & 0 & 0 \\
0 & 0 & 0 & 0 & 1 & 0 & 0 \\
0 & 0 & 0 & 0 & 0 & 1-q & q \\
0 & 0 & 0 & 0 & 0 & 1 & 0 \\
0 & 0 & 0 & 0 & 0 & 0 & 1
\end{array}\right] .
$$

Fiscal policy in the United States serves as a motivating example for this framework. For example, many of the tax provisions originally passed in 2001 and 2003 were set to expire at the end of 2010. Many of the key provisions, however, were temporarily extended, which raised questions as to whether the provisions would again be extended, perhaps permanently. Many of the income tax provisions were ultimately extended at the end of 2012, but not 
without substantial uncertainty leading up to the outcome.

More broadly, as countries face debt projections that grow as a share of GDP, such as the US, households are likely to anticipate an adjustment to tax rates at some point in the future, though are uncertain about the timing. In this case, households form expectations as if in a regime resembling $S_{t}=0$. As debt rises, however, policymakers will eventually focus on reforms to stabilize debt, either due to market or political pressures, and the timing of an adjustment becomes clearer to households. Efforts to begin stabilizing debt, however, still require time to negotiate and are plagued by the inherent uncertainty associated with moving reforms through legislative channels.

The information flow in Figure 4 is intended to capture these elements, consisting of a status quo regime, where households understand fiscal reforms are possible, but the timing is uncertain and likely far into the future. The framework than also captures the impact of the arrival of news, such as a temporary tax extension or credible efforts by policymakers to begin negotiating reforms to stabilize debt, and the associated uncertainty as to how nearterm fiscal issues may be resolved. The approach also captures transitional dynamics, due to a shift in fundamental fiscal parameters, or a permanent extension of temporary fiscal measures, such as a tax cut that was originally enacted to be temporary.

\subsection{Measuring Fiscal Uncertainty}

Given the information structure in Figure 4 and the income tax rule (7), there are two sources of fiscal uncertainty: the intra-regime shock $u_{t}$ and the expiring tax provision process for

$\mu\left(S_{t}\right)$. In order to assess fiscal uncertainty in the economy, consider two measures: the value of income subject to expiring taxes, and the expected future tax burden.

The first, an expiring tax provision index, follows Baker et al. (2013), and measures how much output is subject to expiring taxes. Since expiring taxes are only a near-term possibility between $S_{t}=1$ and $S_{t}=N$, and otherwise the tax intercept is fixed in the 
near-term, the value of income subject to expiring tax provisions are defined as

$$
E T P_{t}=\left\{\begin{array}{cc}
\left(\mu_{1}-\mu_{0}\right) Y_{t} & \text { if } S_{t} \in\{1, \ldots, N\} \\
0 & \text { if } S_{t} \in\{0, N+1, N+2\}
\end{array} .\right.
$$

After an uncertainty shock, tax revenue equals $\left(\mu_{0}+\lambda B_{t-1}+\varepsilon_{t}\right) Y_{t}$, while revenue under the alternate tax regime is $\left(\mu_{1}+\lambda B_{t-1}+\varepsilon_{t}\right) Y_{t}$. The difference is $\left(\mu_{1}-\mu_{0}\right) Y_{t}$ and indicates how much tax revenue would change if taxes expired. Note that, similar to standard estimates of the incidence of taxes such as that by the Congressional Budget Office, the measure $E T P_{t}$ does not take into account the general equilibrium effects of taxes, since it uses a counterfactual tax rate without a corresponding counterfactual output level.

In addition to the expiring tax provision measure, to highlight longer-term implications of taxes, consider the expected present discounted value of all future tax revenue, which is given by

$$
\Gamma_{t}=\mathbb{E}_{t} \sum_{j=0}^{\infty} \beta^{j} \frac{\phi_{t+j}}{\phi_{t}} \tau_{t+j} Y_{t+j},
$$

where $\phi_{t}$ denotes the household's marginal utility of consumption at time $t$. This measure $\Gamma_{t}$ captures the total future tax burden, appropriately discounted, that provides a measure of how expectations of future fiscal policy change over time.

\subsection{Parameter Values and Model Solution}

Table 1 displays the full set of parameter values assuming a unit of time equals a quarter. Many of the parameters follow standard choices from the literature, but a few deserve special attention.

Preferences follow Jaimovich and Rebelo (2009), which allow for varying degrees of the wealth effect on labor supply between the case of no wealth effect (Greenwood et al. (1988)) and a full wealth effect that completely offsets the substitution effect (King et al. (1988)). The preference specification in (1) uses the latter, with a risk aversion of unity $(\gamma=1)$, and 
Table 1: Parameterization

\begin{tabular}{l|l|l}
\hline \hline Parameter & Description & Value \\
\hline$\beta$ & Discount Factor & 0.99 \\
$\gamma$ & Coefficient of Relative Risk Aversion & 1 \\
$\theta$ & Elasticity of Labor & 1.4 \\
$L_{s s}$ & Steady State Labor & 0.33 \\
$\alpha_{1}$ & Frictional Capital Share & 0.15 \\
$\alpha_{2}$ & Frictionless Capital Share & 0.20 \\
$\delta_{1}$ & Depreciation Rate, Frictional Capital & 0.010 \\
$\delta_{2}$ & Depreciation Rate, Frictionless Capital & 0.085 \\
$\varphi$ & Degree of Adjustment Costs & 2 \\
$g$ & Fraction of Government Spending & 0.20 \\
$\lambda$ & Response of Tax Rate to Debt & 0.15 \\
$\rho$ & Serial Correlation of Shock to Tax Rate & 0.9 \\
$\sigma$ & Standard Deviation of Tax Rate Shock & 0.0001 \\
$p$ & Probability of Uncertainty Shock & 0.01 \\
$q$ & Probability that Taxes Adjust & 0.25 \\
$N$ & Length of Fiscal Uncertainty & 4 \\
$\mu_{0}$ & Tax Process Intercept, High Debt Regime & 0.1306 \\
$\mu_{1}$ & Tax Process Intercept, Low Debt Regime & 0.1460 \\
\hline \hline
\end{tabular}

an elasticity of labor parameter $\theta=1.4$. The value of the disutility of labor $\psi$ ensures that labor in the steady state equals $L_{s s}=0.33$.

Motivated by the VAR evidence in Section 2, the two types of capital reflect key differences between structures and equipment. Since structures responds more slowly to uncertainty shocks, $K_{1, t}$ faces adjustment costs governed by $\varphi=2$ as in Jaimovich and Rebelo (2009). House and Shapiro (2008) show various depreciation rates depending on the type of capital. Broadly consistent with their analysis, structures face a depreciation rate of $\delta_{1}=0.01$ and equipment faces a depreciation rate of $\delta_{2}=0.085$. The capital shares $\alpha_{1}=0.15$ and $\alpha_{2}=0.20$ reflect shares of income going to each capital type from the NIPA accounts.

The two probabilities $p$ and $q$ control the likelihood of an uncertainty shock and of an adjustment in tax rates. The baseline parameterization has $p=0.01$, capturing the unlikely nature of fiscal uncertainty episodes, and $q=0.25$, meaning the tax rate changes in onequarter of fiscal uncertainty episodes. The parameter $N$ dictates the length of uncertainty 
about future tax rates, so a value of 4 implies duration of one year. Finally, the choice of $\mu_{0}=0.1306$ and $\mu_{1}=0.1460$ imply steady state marginal tax rates of 0.209 and 0.207 , which correspond to steady state debt-to-GDP ratios of 0.90 and 0.70 , respectively. Note that $\mu_{1}$ exceeds $\mu_{0}$, and corresponds to a lower steady-state marginal tax rate, which occurs because of a lower steady state debt level associated with $\mu_{1}$. So a switch from $\mu_{0}$ to $\mu_{1}$ produces a period of temporarily higher taxes that eventually pays down debt and leads to a lower tax rate in steady state.

Given that the model is a Markov-switching DSGE model with changes that affect the steady state and a large state vector, linearized solution methods that account for the regime switching such as Davig and Leeper (2007) and Farmer et al. (2011) may prove insufficient. The following results use the perturbation method for Markov-switching DSGE models of Foerster et al. (2013), with a second-order approximation used to improve accuracy.

\subsection{Intra-Regime Shock}

Before discussing the impact of a fiscal uncertainty shock, first consider the impact of a temporary shock to the tax rate, $u_{t}$, without any uncertainty about future tax regimes. In this case, $p=0$, so households expect $\mu_{0}$ to govern the steady-state tax rate forever. Figure 5 illustrates the impact of a 0.1 percentage point increase in the tax rate. The increase

has intuitive effects, as both types of investment decline due to a lower expected after-tax rate of return. Investment in structures responds with a lag due to costly adjustment, while investment in equipment falls on impact. Employment also declines due to the lower aftertax real wage, which pulls output lower. The initial increase in the marginal tax rate causes debt to fall, which eventually leads to a lower tax rate and then to a recovery in output, consumption, investment, and employment as the shock dissipates. 
Figure 5: Response to an Intra-Regime Tax Shock
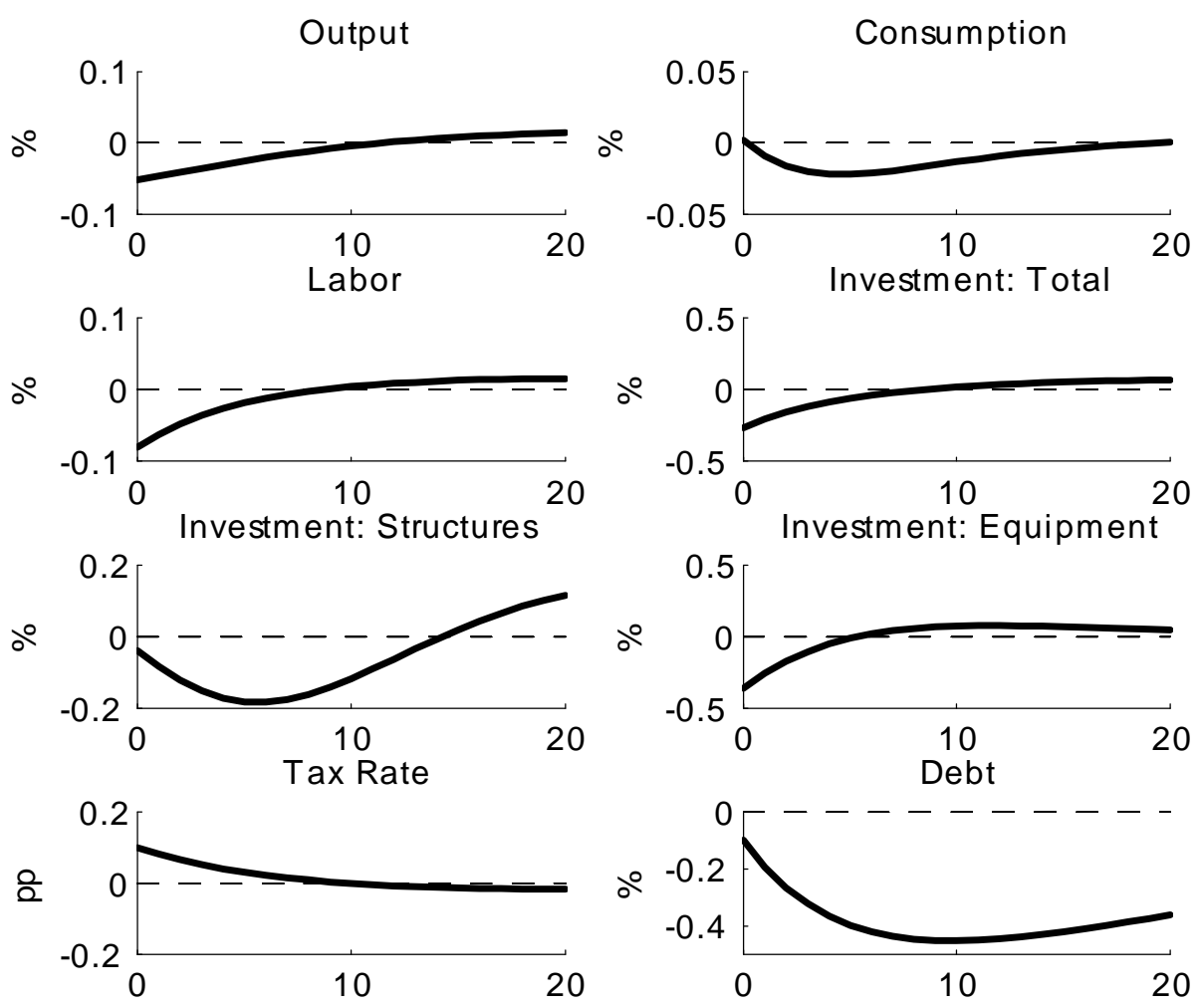

\section{A Fiscal Uncertainty Shock}

This section reports baseline results from the model incorporating the information structure from Figure 4. In this setting, households respond to the arrival of new information about future taxes. A fiscal uncertainty shock is the arrival of news that tax rates may change at some point in the future. As an example, this framework can capture a situation were a given average tax rate may have been scheduled to "sunset" at some point in the future, though households understand there is a possibility, perhaps for political reasons, that tax rates will actually be left unchanged. ${ }^{1}$

\footnotetext{
${ }^{1}$ As a practical example, consider the situation at the start of 2011. Congress passed in December of 2010 legislation that temporarily extended several tax provisions that were set to expire at the end of the year. The legislation also introduced additional temporary measure, such as a one-year reduction in the FICA payroll tax rate. The payroll tax cut, for example, was ultimately extended for one year, but then expired at the end of 2012 and contributed to the confluence of fiscal tightening measures scheduled to begin in 2013 commonly known as the Fiscal Cliff.
} 
The following results focus on two aspects: how the arrival of new information affects the economy leading up to the period when uncertainty is resolved, as well as the response after resolution. If the average tax rate is ultimately left unchanged, then the fiscal uncertainty shock amounts to noise that nonetheless temporarily induces changes to household decisions. If the average tax rate does change, then households must complete the adjustment to the new steady state that only partially began upon the arrival of the initial information.

\subsection{Fiscal Noise}

Figure 6 illustrates the impact of a fiscal uncertainty shock that ultimately does not result in a change to the tax policy rule. A shift to the regime where households know there is a possibility of tax rates moving higher in the future-after 4 periods in this case-generates an immediate decline in both types of investment and employment. Investment in structures drops with a lag due to costly adjustment, while investment in equipment falls sharply. Both types of investment decline due to expectations that the after-tax rate of return to capital may be lower in the future in the event that tax rates do ultimately move higher. The allocation away from investment allows consumption to temporarily increase, similar to McGrattan (2012).

The distorting effects of future taxes induce households to consume more and provide less labor. The substitution effect away from investment dominates the wealth effect that would otherwise suggest lower consumption and more labor due to higher future taxes. In addition, a substitution effect away from future labor to current labor in order to avoid taxation is overwhelmed by a desire to disinvest: households do not want to work more before taxes may increase because a lower investment incentive means that any further labor income would support already-high consumption.

The decline in labor supply causes output to decline in a similar manner. The loss in output leads to a lower tax base, which causes debt to rise and triggers an endogenous, though modest, increase in the tax rate. 
Figure 6: Response to an Uncertainty Shock
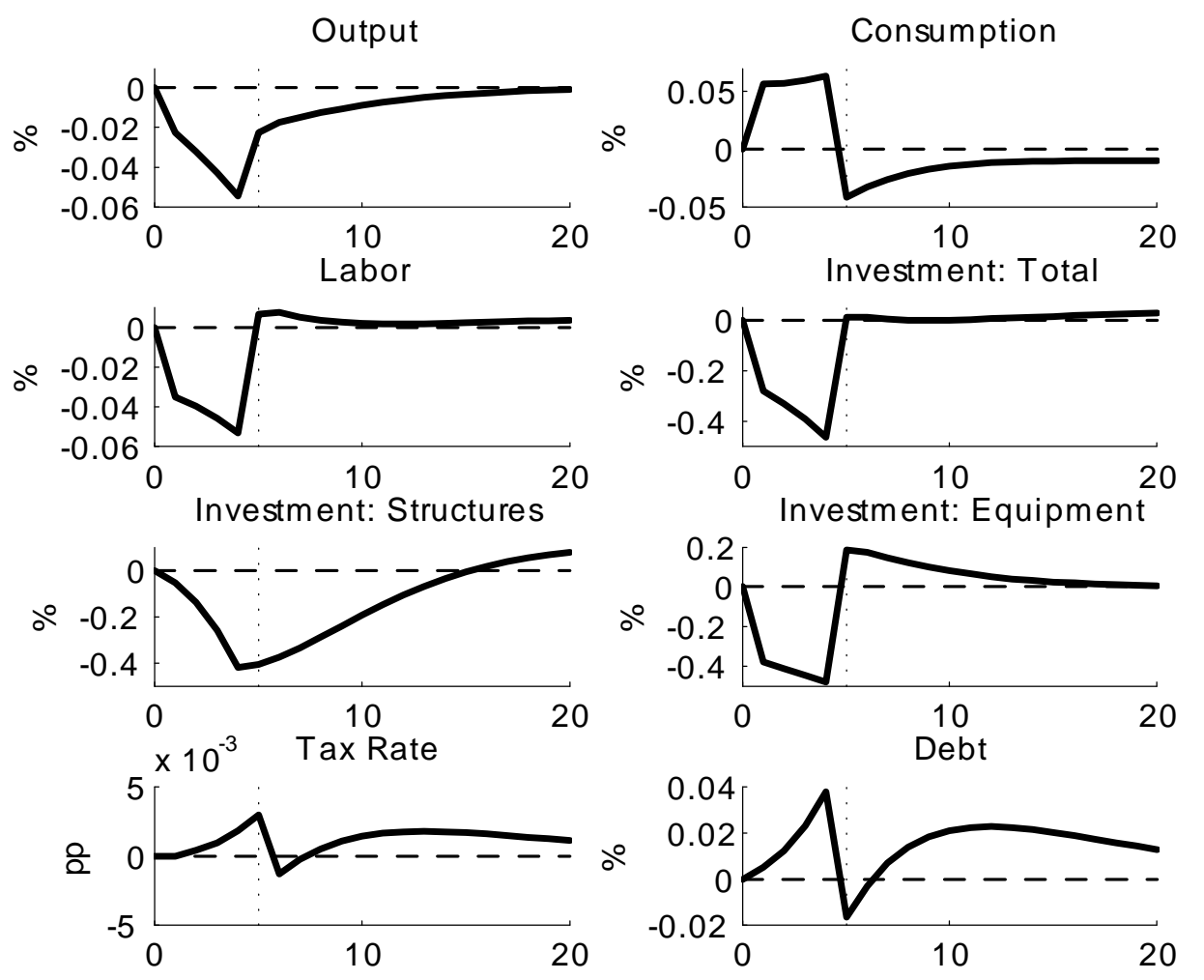

In this example, tax rates are ultimately held at $\mu_{0}$, but the spectre of higher taxes on capital income in the future causes households to substitute away from investment and labor and towards consumption and leisure. In period $t=5$, tax rates do not adjust, indicating to households and firms that the tax rate intercept will remain at $\mu_{0}$ indefinitely.

Upon the resolution of uncertainty, investment immediately increases, driven by a bounce back in equipment, while investment in structures has a more gradual rebound. The incentive to invest, now stronger because of an expectation that tax rates will remain lower in the future along with the need to offset the relative under-investment during the period of uncertainty, leads to a reallocation away from consumption towards investment starting in the period when the uncertainty is resolved. The reallocation back towards investment causes consumption to decline and labor to increase.

In terms of a rebound following the resolution of the uncertainty, any snap back in activity 
Figure 7: Response to an Adjustment in Tax Rates
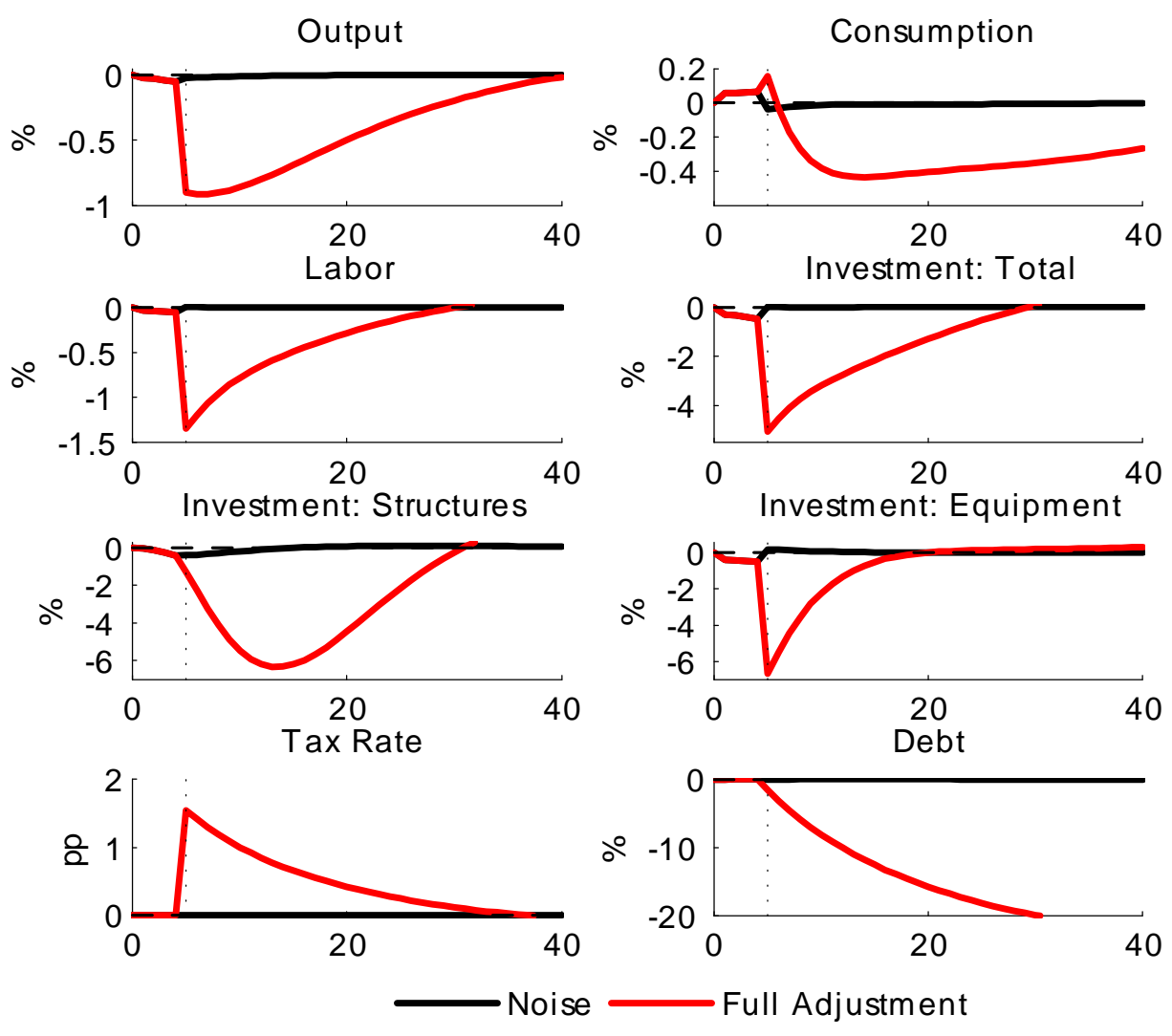

will be governed, in part, by the amount investment subject to adjustment costs. A heavy concentration of investment in structures, for example, will result in a gradual recovery. In contrast, equipment investment and employment show sharp recoveries starting in the period when uncertainty is resolved.

\subsection{Full Fiscal Adjustment}

Alternatively, policymakers may implement reforms after the $N$ period horizon. In this case, Figure 7 illustrates how the economy responds to an uncertainty episode that is followed by a change in the tax regime relative to the case of fiscal noise, where no fiscal adjustment occurred. The differences in the two paths begin in period five, which is the period when uncertainty is resolved.

The shift sets in motion household decisions to complete the adjustment that began when 
the uncertainty shock first hit. Equipment investment and employment drop sharply after the rule changes, structures adjust more gradually due to adjustment costs. Output also declines sharply, but not as fast as the drop in investment, so consumption temporarily rises reflecting the desire to disinvest. Given the shift in policy, the tax rate increases causing a steady decline in debt. Eventually, debt falls sufficiently to endogenously pull the tax rate lower than prior to the fiscal uncertainty episode and after a prolonged period, results in a higher capital stock and level of output.

\subsection{Measuring a Fiscal Uncertainty Shock}

Now consider what the fiscal noise scenario in Figure 6 and the full fiscal adjustment scenario in Figure 7 imply for the measures of fiscal uncertainty described in Section 3.5. Figure 8 displays how the expiring tax provisions measure and the expected tax burden respond to the two scenarios.

When the fiscal uncertainty shock hits, the expiring tax provisions measure increases and remains roughly constant for four periods. In Figure 6, output is changing slightly in these periods, and so the expiring tax provisions measure changes slightly as well, but by an imperceptible amount. When uncertainty is resolved, the measure decreases back to zero, as there is no longer any chance of tax shifts in the future. In both scenarios, since the period between the uncertainty shock and the resolution are identical, so is the measure of expiring tax provisions.

The expected tax burden, however, does differ depending on the resolution of uncertainty. The tax burden jumps when the fiscal uncertainty shock first hits regardless of how it is resolved, but then rises sharply after $N$ periods if tax rule changes and households complete the adjustment to the new fiscal regime. In the fiscal noise scenario, the tax burden measure falls after $N$ periods in response to the unchanged tax policy, whereas the tax burden jumps in the scenario when the rule actually does shift. 
Figure 8: Measures of Fiscal Uncertainty

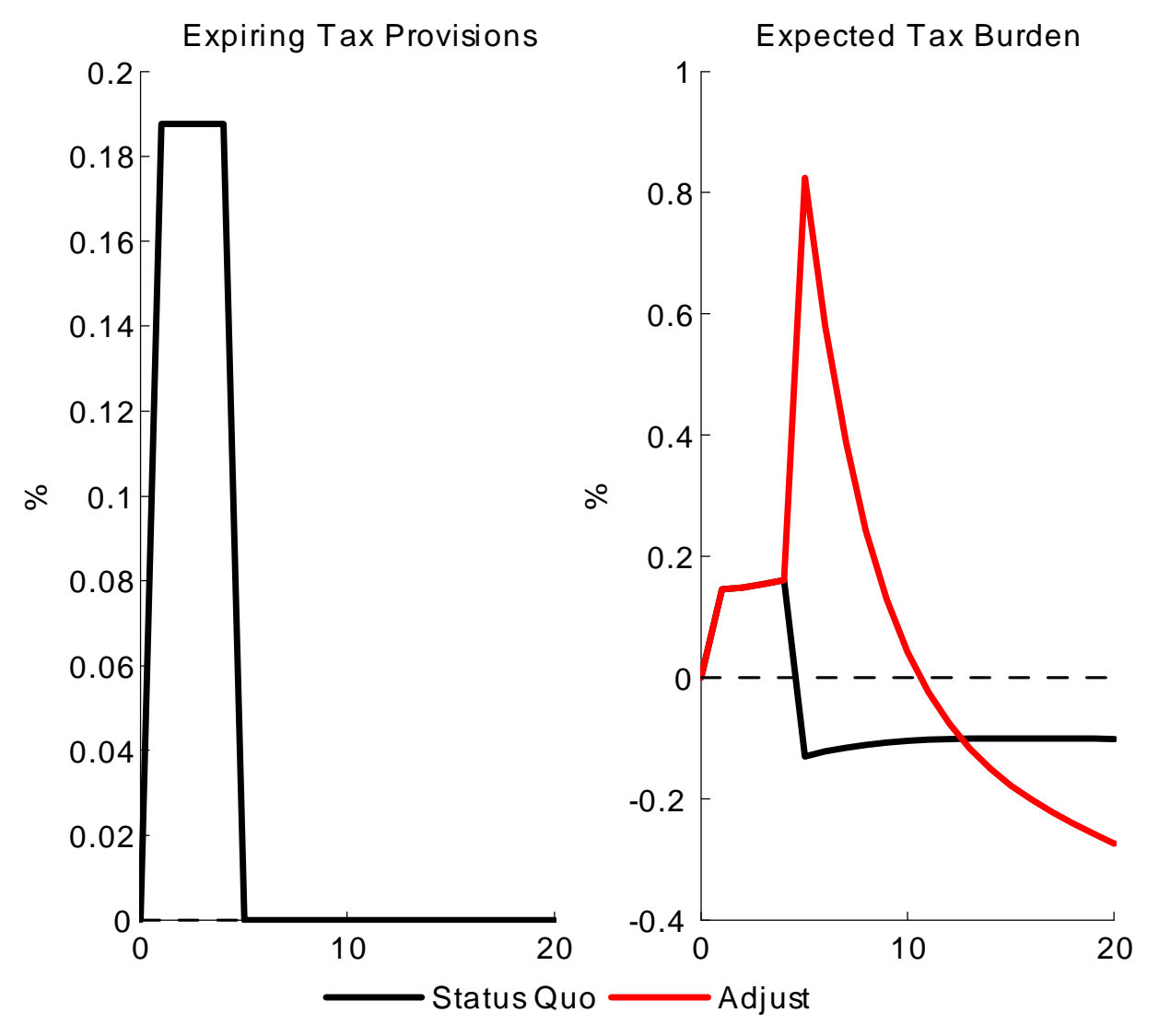

\section{$5 \quad$ Expectations and the Effects of Uncertainty}

Having presented the baseline results which consider the effects of an uncertainty shock, now consider the interaction between expectations and uncertainty. Since households and firms understand the probability of receiving an uncertainty shock $p$, the duration of the uncertainty episode $N$, and the probability that the tax rate adjusts $q$, changes in these parameters amount to altering expectations, and will influence economic outcomes before and after an uncertainty shock.

This section considers the effects of these three different parameters on the model. The first section examines the effects of expectations on the uncertainty episode by repeating the fiscal noise scenario of Section 4.1 under different fiscal adjustment probabilities $q$. The second section investigates the effects of the duration of uncertainty in the fiscal noise scenario 
by increasing $N$, which is the length between the uncertainty shock and the resolution. The third section analyzes how expectations of the likelihood of uncertainty shocks $p$ affects behavior and economic outcomes in the status quo regime $S_{t}=0$.

\subsection{Fiscal Uncertainty and Expectations of Adjustment}

Once the fiscal uncertainty shock hits, the magnitude of the adjustment during the $N$ period horizon depends primarily on the probability $q$ that households attach to a shift in the tax rule. The baseline parameterize sets $q=0.25$, so households only partially adjust to a potential change in the tax rule over the $N$ period horizon. If $q=1.0$, for example, then the uncertainty shock becomes a news shock, and households have complete knowledge about the future tax rule, so would begin fully incorporating higher taxes after $N$ periods into their decisions.

Figure 9 compares dynamics across different values of $q$. The higher $q$, the greater households attached to the rule shifting after $N$ periods. As $q$ rises, the adjustment to an uncertainty shock is more heavily front loaded and therefore, the impact of the shock is larger. In contrast, if $q$ is lower, households place a low probability on a future adjustment so only modestly adjust their behavior when the uncertainty shock hits. One aspect of the dynamics of interest is the extent of payback, or the rebound, if the tax rule ultimately does not change. In each case, labor rebounds modestly, but not enough to pull up output. Instead, the lower capital stock weighs on output after uncertainty is resolved, so households reduce consumption to rebuild the capital stock. Stronger rebounds occur when the labor supply elasticity is higher or the share of capital subject to adjustment costs is reduced.

Figure 10 shows how the two measures of fiscal uncertainty change as $q$ changes. The expiring tax provisions graphs are practically indistinguishable, so the value of income subject

to expiring taxes does not change as $q$ changes. Since Figure 9 highlights that changes in $q$ do have significant effects on the impact of an uncertainty shock, the analysis suggests a caveat to the Baker et al. (2013) expiring tax provisions index shown in Figure 1: the value 
Figure 9: Response to an Uncertainty Shock Under Alternative Expectations about Adjustment
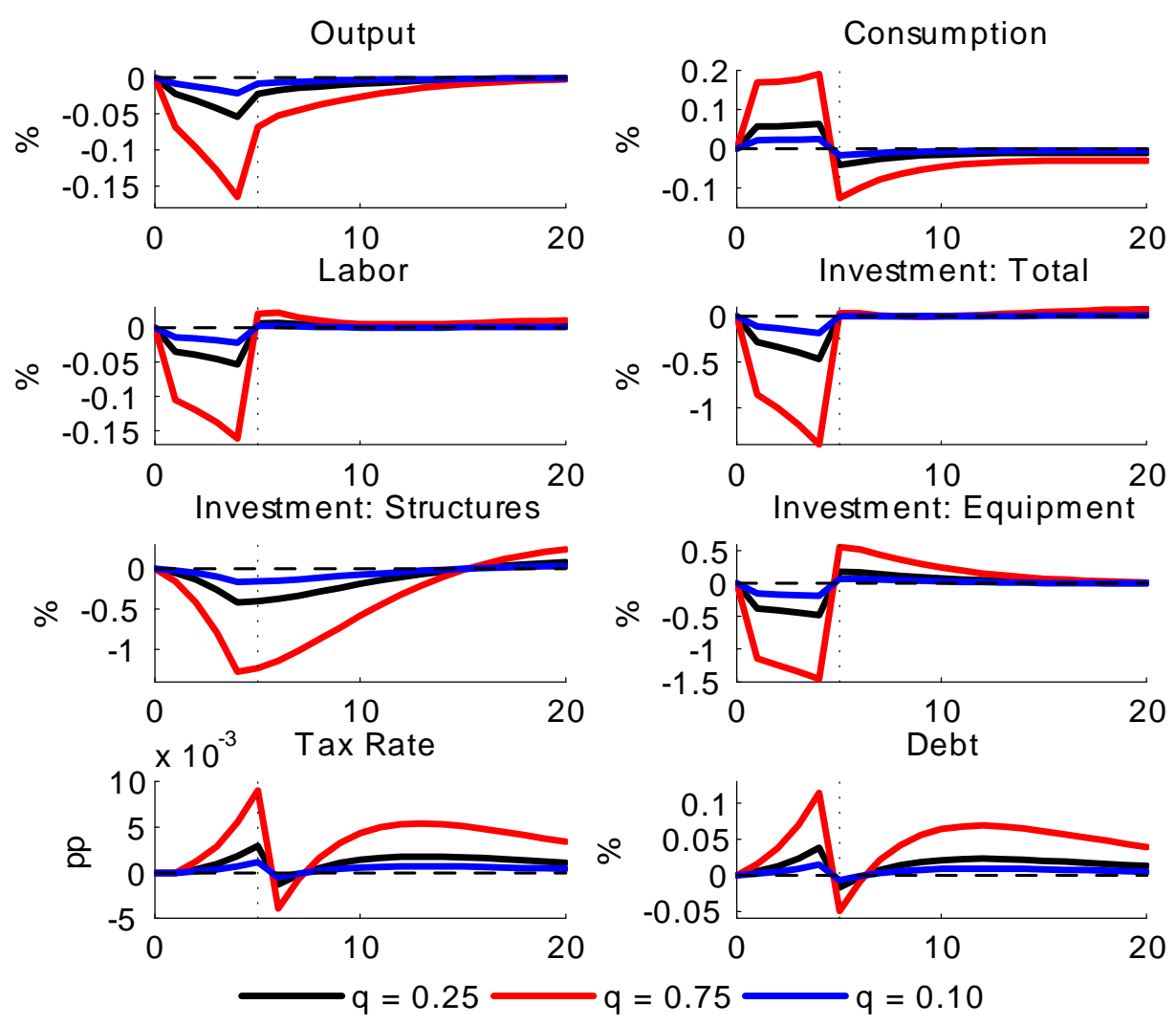

of tax provisions is less important than the probability that adjustment takes place.

The expected tax burden plot in Figure 10 highlights how, when an uncertainty shock is realized, expected future taxes responds significantly based upon the expectations of adjustment. With higher $q$ households have a higher expected tax burden prior to the uncertainty shock, reflecting their rational expectations about receiving an uncertainty shock and the probability of adjustment. When the shock is realized, higher $q$ moves the expected tax burden a larger degree, since households expect adjustment. When adjustment doesn't occur, the tax burden falls significantly. These changes in expected future taxes produce the large swings in investment seen in Figure 9. 
Figure 10: Measures of Fiscal Uncertainty Under Alternative Expectations about Adjustment

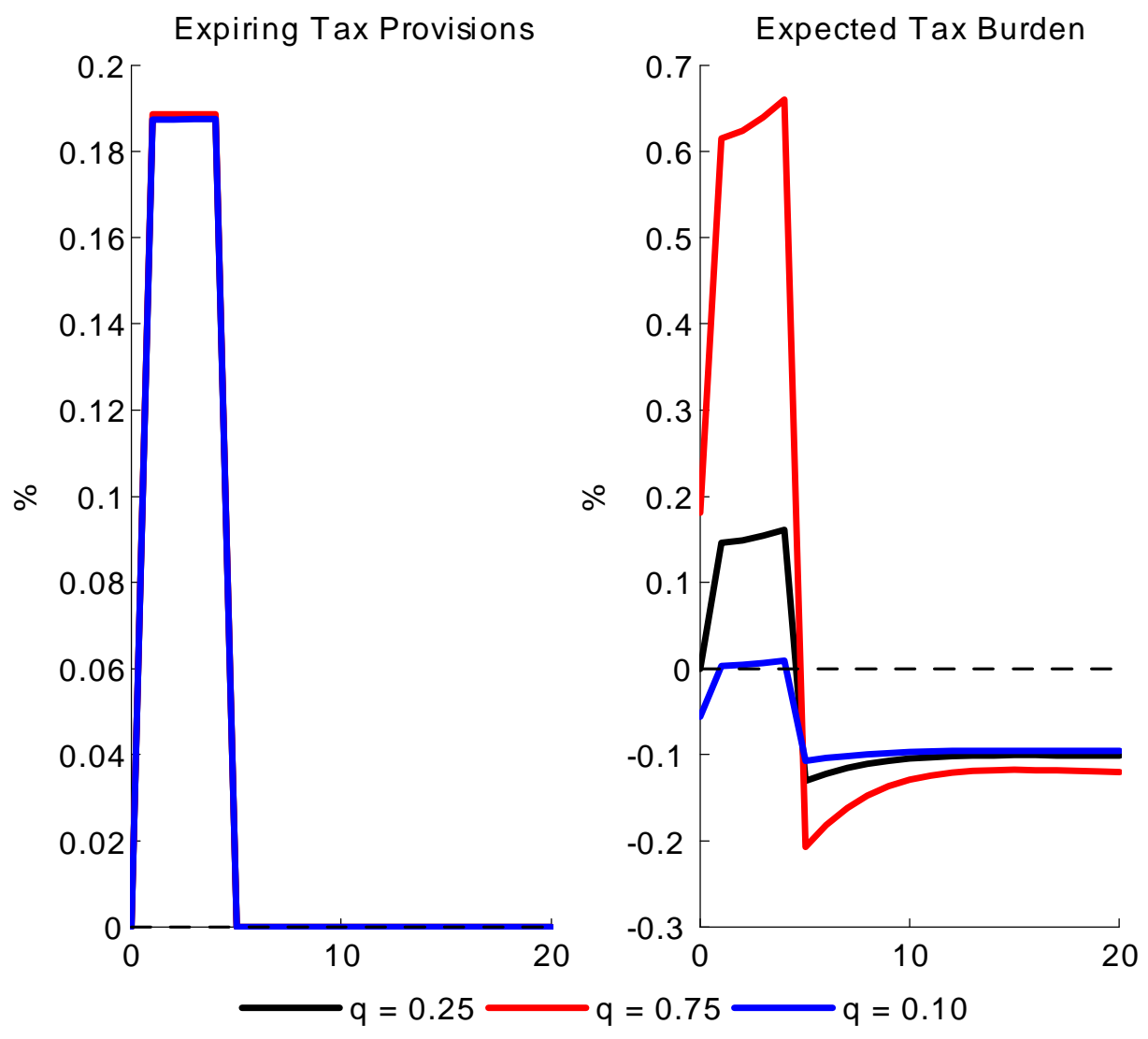

\subsection{Duration of Fiscal Uncertainty}

The baseline results have fiscal uncertainty episodes lasting for $N=4$ periods, and during this time the economy experiences lower labor, investment, and output as it braces for a possible switch in the tax regime. In the baseline calibration, uncertainty lasts for a year, but one concern whether longer spells of uncertainty produce larger declines in economic activity, or if they simply produce a more drawn-out decline. Figure 11 compares the baseline case with one in which $N=8$, so uncertainty lasts twice as long.

During the period of uncertainty, output, labor, and both investment types have similarly sized troughs and consumption has a similarly sized boom across the two durations. In the longer duration case, the economy experiences a longer decline. At the resolution date, the economies across the two specifications are at the same state, implying that households have 
Figure 11: Response to an Uncertainty Shock under Alternative Uncertainty Durations
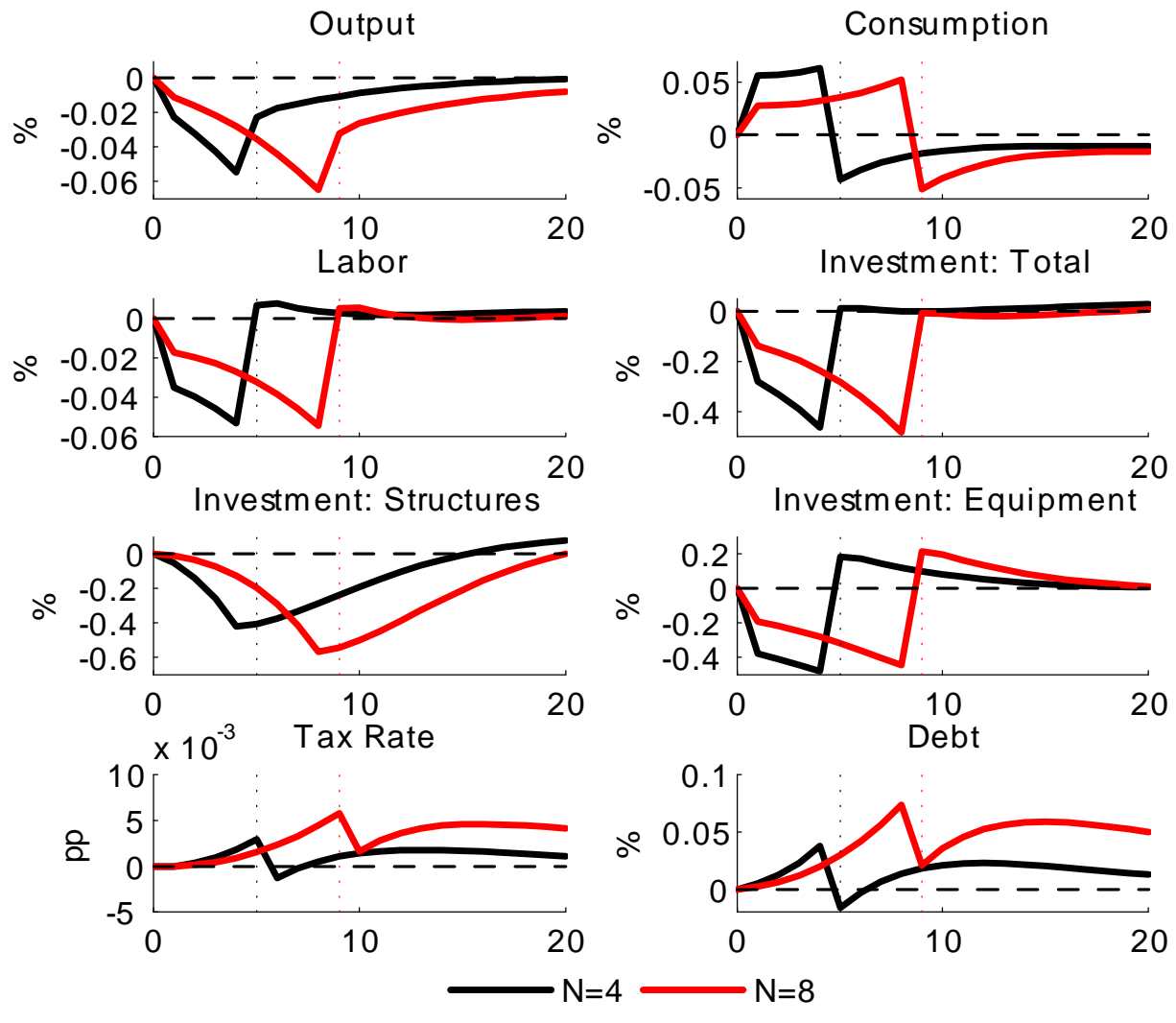

an objective for their capital holdings and use the entire uncertainty episode as an adjustment period. When the tax rate ends up not adjusting, households build up investment and supply labor at a rate that is comparable regardless of the duration of uncertainty.

One potentially important difference is that longer uncertainty spells lead to a larger buildup in debt, which produces slightly higher taxes even when fiscal adjustment does not occur. This result implies that particularly lengthy uncertainty spells may lead to higher taxes for long periods of time, even in the case when the tax rule is fixed in the near term.

\subsection{Long Run Effects of Fiscal Uncertainty}

A more pernicious implication of fiscal uncertainty arises from the impact on the distributions of variables before an uncertainty shock occurs. As households make decisions in the initial, or status-quo, regime $\left(S_{t}=0\right)$, the probability of higher future taxes persistently weighs on 
Figure 12: Stochastic Steady State of the Status Quo Regime as q Varies
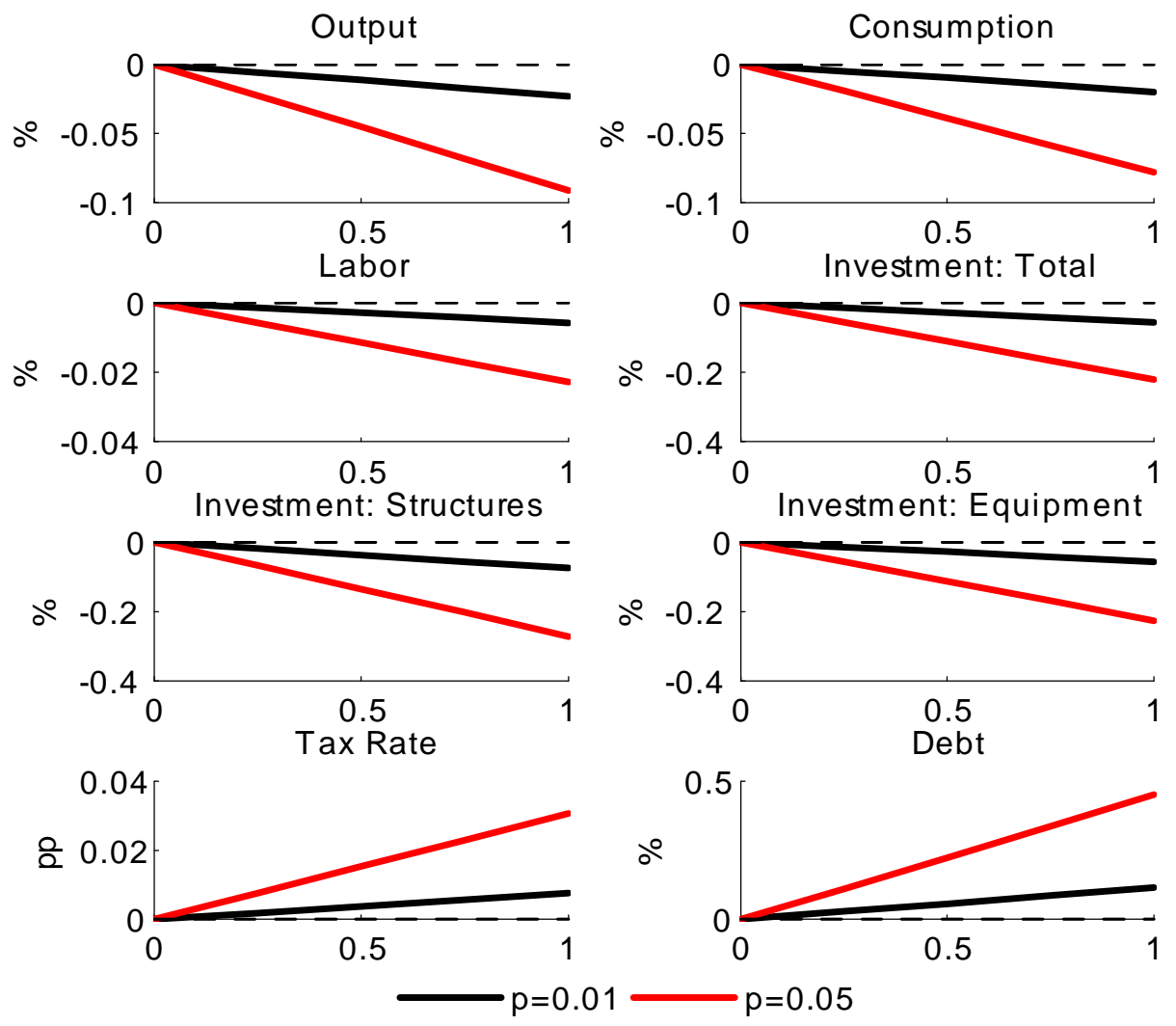

the level of investment and capital stock. So while $q$ was a key parameter in governing the transitional dynamics following a fiscal uncertainty shock, $p$ is more relevant in affecting the stochastic steady-state levels conditional on the status-quo regime. One interpretation of the parameter $p$ is that it conveys the general level of fiscal uncertainty in the economy. If $p$ is relatively high, households are more likely to face a fiscal uncertainty shock that may result in higher taxes after $N$ periods. As Figure 12 illustrates, the stochastic steady-state levels of investment, employment, consumption and output fall below steady state levels in economies with no uncertainty about future fiscal regimes (i.e. $p=0$ ).

The framework provides a clear mechanism for how post-recession fiscal policy, which Figure 1 illustrates was often plagued by fiscal uncertainty, as well as how longer-term fiscal uncertainty may be weighing on both the current economic recovery and longer-term economic growth. For example, projections from the Congressional Budget Office raise ques- 
tions about the stability of debt dynamics over a multi-decade horizon. Such projections raise uncertainty regarding future taxes, which map into the parameter $p$, and as a result, weigh on current capital formation.

\section{Conclusion}

This paper considered the effects of expiring tax provisions such as the recent Fiscal Cliff in the US. Empirically, a rise in economic policy uncertainty lowers employment and investment, and produces a rapid decline in equipment and a slow decline in structures investment. In the model, an uncertainty shock pushes the economy towards a date when the tax rate may change. This uncertainty generates declines in investment, employment, and output, though investment adjustment costs mute the response of investment, similar to the empirical response of investment in structures.

The results highlight that uncertainty shocks such as the Fiscal Cliff episode lower economic activity. In addition, they show that expectations about future policy have important implications. When an uncertainty shock occurs, the adverse response in output, employment, and investment depends upon how long the uncertainty is expected to last and the likelihood of an adjustment in taxes. In addition, the potential for uncertainty shocks has negative effects on the economy. If uncertainty shocks are viewed as being more likely, the economy will have a permanently lower level of activity even absent those shocks. 


\section{References}

Baker, S., N. Bloom, and S. Davis (2013). Measuring Economic Policy Uncertainty. Working Paper.

Basu, S. and B. Bundick (2012). Uncertainty Shocks in a Model of Effective Demand. Working Paper 774, Boston College.

Bianchi, F. (2012). Evolving Monetary/Fiscal Policy Mix in the United States. American Economic Review 102(3), 167-72.

Bianchi, F. and L. Melosi (2013). Dormant Shocks and Fiscal Virtue. In NBER Macroeconomics Annual, Volume 28 of NBER Chapters. National Bureau of Economic Research, Inc.

Bloom, N. (2009). The Impact of Uncertainty Shocks. Econometrica 77(3), 623-685.

Bloom, N., M. Floetto, N. Jaimovich, I. Saporta-Eksten, and S. J. Terry (2012). Really Uncertainty Business Cycles. Working Paper 182545, NBER.

Born, B., A. Peter, and J. Pfeifer (2013). Fiscal News and Macroeconomic Volatility. Journal of Economic Dynamics and Control 37(12), 2582-2601.

Christiano, L., R. Motto, and M. Rostagno (2014). Risk Shocks. American Economic Review $104(1), 27-65$.

Chung, H., T. Davig, and E. Leeper (2007). Monetary and Fiscal Policy Switching. Journal of Money, Credit and Banking 39(4), 809-842.

Davig, T. (2004). Regime-Switching Debt and Taxation. Journal of Monetary Economics 51(4), 837-859.

Davig, T. and E. Leeper (2007). Generalizing the Taylor Principle. American Economic Review 97(3), 607-635. 
Davig, T. and E. Leeper (2011). Monetary-Fiscal Policy Interactions and Fiscal Stimulus. European Economic Review 55(2), 211-227.

Farmer, R., D. Waggoner, and T. Zha (2011). Minimal State Variable Solutions to MarkovSwitching Rational Expectations Models. Journal of Economic Dynamics and Control 35(12), 2150-2166.

Fernández-Villaverde, J., P. Guerrón, K. Kuester, and J. F. Rubio-Ramírez (2012). Fiscal Volatility Shocks and Economic Activity. Working Paper.

Fernández-Villaverde, J., P. Guerrón, J. F. Rubio-Ramírez, and M. Uribe (2011). Risk Matters: The Real Effects of Volatility Shocks. American Economic Review 101, 2530-61.

Foerster, A., J. Rubio-Ramirez, D. Waggoner, and T. Zha (2013). Perturbation Methods for Markov Switching DSGE Models. Working Paper 13-01, Federal Reserve Bank of Kansas City.

Greenwood, J., Z. Hercowitz, and G. Huffman (1988). Investment, Capacity Utilization, and the Real Business Cycle. American Economic Review 78(3), 402-417.

Hollmayr, J. and C. Matthes (2013). Learning About Fiscal Policy and the Effects of Policy Uncertainty. Working Paper 13-15, Federal Reserve Bank of Richmond.

House, C. and M. Shapiro (2008). Temporary Investment Tax Incentives: Theory with Evidence from Bonus Depreciation. American Economic Review 98(3), 737-68.

Jaimovich, N. and S. Rebelo (2009). Can News about the Future Drive the Business Cycle. American Economic Review 99(4), 1097-1118.

King, R., C. Plosser, and S. Rebelo (1988). Production, Growth, and Business Cycles: I. The Basic Neoclassical Growth Model. Journal of Monetary Economics 21(2-3), 195-232.

Leduc, S. and Z. Liu (2012). Uncertainty Shocks are Aggregate Demand Shocks. Working Paper 2012-10, Federal Reserve Bank of San Francisco. 
McGrattan, E. (2012). Capital Taxation During the U.S. Great Depression. The Quarterly Journal of Economics 127(3), 1515-1550.

Richter, A. and N. Throckmorton (2013). The Consequences of Uncertain Debt Targets. Auburn Economics Working Paper Series 2013-18, Department of Economics, Auburn University.

Schmitt-Grohé, S. and M. Uribe (2012). What's News in Business Cycles. Econometrica $80(6), 2733-2764$. 